\section{Understanding the relationship between socioeconomic status, smoking cessation services provided by the health system and smoking cessation behavior in Brazil}

\author{
Entendendo as relações entre posição \\ socioeconômica, oportunidades oferecidas pelo \\ sistema de saúde e comportamentos para a \\ cessação ao fumo no Brasil
}

\author{
Comprensión de la relación entre la situación \\ socioeconómica, las oportunidades que ofrece \\ el sistema de salud y los comportamientos para \\ dejar de fumar en Brasil
}

\begin{abstract}
Increasing the effectiveness of smoking cessation policies requires greater consideration of the cultural and socioeconomic complexities of smoking. The purpose of this paper is to explore the association between socioeconomic status and "selected midpoints" linked to smoking cessation in Brazil. Data was collected from a representative sample of urban adult smokers as part of the ITC-Brazil Survey (2009, $N=1,215)$. After controlling for age and gender, there were no statistically significant differences quit attempts in the last six months between individuals with different socioeconomic status. However, smokers with high socioeconomic status visited a doctor 1.54 times more often than those with low socioeconomic status ( $p$-value $=0.017)$, and were also 1.65 times more likely to receive advice to quit smoking ( $p$-value = 0.025). Our results demonstrate that disparities in health and socioeconomic status are still a major challenge for policymakers to increase the population impact of tabacco control actions worldwide.
\end{abstract}

Smoking Cessation; Health Services Accessibility; Health Policy
André Salem Szklo ${ }^{1}$

James F. Thrasher 2

Cristina Perez 3

Valeska Carvalho Figueiredo 4

Geoffrey Fong 5

Liz Maria de Almeida 1

\section{Resumo}

O aumento da efetividade das políticas voltadas para a cessação ao fumo requer um maior entendimento das questões culturais e socioeconômicas que fazem parte do universo dos fumantes. O objetivo deste artigo é explorar a associação entre status socioeconômico e "pontos intermediários selecionados" relacionados à cessação de fumar no Brasil. Com base na pesquisa ITC-Brasil, foram coletadas informações de uma amostra representativa da população urbana adulta de fumantes (2009, $N=1.215)$. Após ajustar por idade e sexo, não foram encontradas diferenças estatisticamente significativas nas tentativas de parar nos últimos 6 meses segundo status socioeconômico. Entretanto, fumantes com elevado status socioeconomico visitaram um médico 1,54 vez a mais do que aqueles com baixo status socioeconômico $(p=0,017)$ e também receberam 1,65 vez mais aconselhamento para parar de fumar ( $p=0,025)$. Os achados indicam que disparidades entre saúde e status socioeconômico ainda representam um desafio para os gestores no sentido de aumentar o impacto populacional das ações de controle do tabaco no mundo.

Abandono do Hábito de Fumar; Acesso aos Serviços de Saúde; Política de Saúde 


\section{Introduction}

Tobacco use is the second leading cause of mortality in the world 1. Despite this, the tobacco use epidemic and associated disease burden is growing, particularly in low and middle-income countries.

The World Health Organization Framework Convention on Tobacco Control (WHO FCTC) was developed as a response to the globalization of the tobacco epidemic ${ }^{2}$. This treaty establishes a set of targets and activities to be followed by the participating countries in order to reduce both tobacco production and consumption.

Brazil has implemented a broad set of legislative, health care, educational and economic interventions to address tobacco use since 1986, making it a world leader in tobacco control and one of the most successful countries in reducing tobacco use (from $34.8 \%$ in 1989 to $18.2 \%$ in 2008) 3 . Interventions to reduce the burden and prevalence of tobacco use include national smoking cessation campaigns through the massmedia, prominent health warnings with graphic pictures on tobacco product packaging, and free telephone counseling for smoking cessation.

Additionally, in accordance with the postulates of article 14 of the WHO FCTC encouraging the implementation of effective measures to promote cessation of tobacco use and the promotion of adequate treatment for tobacco dependence, the Brazilian Unified National Health System (SUS, acronym in Portuguese) supports cognitive-behavioral and pharmacological treatment for smoking cessation ${ }^{3}$. The SUS, created in 1988 by the Federal Constitution, is one of the largest public health systems in the world. The system covers everything from outpatient care to organ transplants and aims to provide complete, universal and free access to the entire population. As the first contact with the health system occurs, preferentially, through primary care (i.e., health care units, including family, school and company health units), the National Tobacco Control Program has concentrated efforts on the creation of partnerships with state and municipal health departments and civil society organizations in order to promote smoking cessation in health units, schools and the workplace. Thus, doctors, nurses, psychologists, dentists, social workers and other health professionals are sensitized to the need to investigate the smoking status of their patients during routine visits and to offer support for smoking cessation. After this stage, the patient may be advised to seek more comprehensive treatment at specialized hospitals and clinics.

In spite of the availability of smoking cessation services in Brazil, high mean nominal in- come relative to most other countries, and considerable poverty reduction since the 1980s ${ }^{4}$, the United Nations' Human Development Index shows that there is still room for improvement in health care delivery and access in Brazil 5. Underfunding, fiscal stress and the lack of priority given to the health sector have contributed to a progressive deterioration of health care services, and an unequal distribution of funding across regions 6 . As a consequence, people from lower income experience more difficulties in getting regular access to health services and use them more for acutte care, when smoking cessation advice is less likely to occur 7 . It is therefore possible that unequal access to quality preventative health care exacerbates the disproportionate nature of smoking prevalence in Brazilian society. For example, in 2008, overall prevalence of smoking among individuals aged 18 years and over was $18.2 \%$, whereas prevalence among individuals with the lowest level of education (i.e., less than one year of schooling) and those in the lowest income bracket (i.e., those earning less than a quarter of the minimum monthly salary) was $25.9 \%$ and $25.8 \%$, respectively. Furthermore, although overall smoking prevalence in Brazil was reduced by half between 1989 and 2008, one of the lowest relative reductions was observed among individuals with lower educational levels 3 . It is important to note that, to date, few countries have developed comprehensive smoking cessation support systems that focus on underprivileged people and include easy access to treatment 8 .

To increase the effectiveness of smoking cessation policies and programs, particularly those aimed at reducing the socioeconomic disparities related to smoking, it is necessary to give greater attention to the cultural and socioeconomic complexities of smoking ${ }^{9}$. To address such disparities in Brazil, it is necessary to understand the relationships between socioeconomic status, smoking cessation services provided by the health system and smoking cessation behavior.

The purpose of this paper is to explore the association between socioeconomic status and "selected midpoints” linked with successful smoking cessation (e.g., attempts to quit smoking and smoking cessation counseling received from a doctor). As an upper-middle-income country with a longer history of tobacco prevention programs than other countries, the Brazilian experience is likely to offer lessons for other countries that have ratified and are implementing the WHO FCTC, particularly Article 14 which encourages measures concerning tobacco dependence and cessation. 


\section{Methods}

Brazil is a member of the International Tobacco Control Policy Evaluation Project (ITC Project), which is a research collaboration of over 20 countries, involving over $50 \%$ of the world's population and over $70 \%$ of the world's tobacco users. The overall objective of the ITC Project is to evaluate the impact of WHO FCTC policies through the use of longitudinal cohort surveys administered in each ITC country adult smokers and, in the majority of countries, to adult non-smokers. The survey also include smokeless tobacco users, in countries where relevant.

The first wave of the ITC Brazil Survey was conducted between April and June 2009 with a representative sample of adult (aged 18 years and over) smokers.

This survey was conducted through telephone-administered questionnaires with adult smokers living in three of the four largest cities in Brazil: Rio de Janeiro and São Paulo, the two richest cities in Brazil located in the Southeast Region of the country, and Porto Alegre, located in South Region which is responsible for almost $100 \%$ of the country's tobacco production. The sampling process consisted of systematically selecting telephone lines in each of the cities, stratified according to city area, from an electronic registry provided by the Brazilian company Expertise, which also conducted the fieldwork. The selected telephone lines were then re-selected and divided into sub-samples to reproduce the same proportion of telephone lines for each city area. These replicate samples were created to ensure the quality of data and to reduce potential calling order bias. In households with multiple eligible respondents, the Next Birthday Method of Respondent Selection was used to select a single respondent 10 . No substitution within household was allowed, except when it was known that the selected respondent would be absent for the entire duration of the fieldwork.

Householes were called until the planned 400 smokers by city were interviewed. This sample size was large enough to obtain reliable estimates of the main tobacco-related variables analyzed by the survey and of the outcomes evaluated by this study (i.e., a 95\% confidence interval with a margin of error of three percentage points) 11 .

A detailed description of the methods used by the ITC Brazil Survey have been published elsewhere 12 . The household contact rate was $31.7 \%$, as $68.3 \%$ of telephone lines were either not in service, non-residential, fax lines, or in vacant houses. The cooperation rate among individuals who smoked at least monthly and who had smoked at least 100 cigarettes in their entire lifetime was
$85.2 \%$; i.e., $14.8 \%$ of eligible smokers refused to give informed consent and/or hung up before the end of the interview.

The ITC Brazil Survey included information about the socio-demographic characteristics of individuals, tobacco consumption and help received for smoking cessation. Respondents were asked if they had visited a doctor or other health professional during the six months prior to the interview and those who had were asked if this health professional had given any kind of advice or help concerning quitting smoking. Respondents were also asked to provide the following information: if they had received advice regarding quitting smoking, pamphlets or brochures on how to quit; if they had been referred to another service to help them quit; if they had been prescribed a medication to help them stop smoking, and if they had called the free smoking cessation telephone counseling service. Participants reported the number of years of schooling group [elementary school or less (0 to 4 years); secondary or incomplete high school (5 to 10 years); and high school or further education (11 years and over)]. Participants also reported their monthly household income grouped [low (less than three minimum monthly salaries, < US\$ 750); medium (between three and 10 minimum monthly salaries, US\$ 750 to US\$2,500); and high (10 or more minimum monthly salaries, US\$ 2,500 or over)].

In addition to examining each variable separately, we have combined the variables "education" and "income", as it may increase the construct validity of socioeconomic position 13,14. Thus, we have summed the categories of educational level (coded 0 to 2) and monthly income (coded 0 to 2) to a new "variable" called socioeconomic status, as follows: low (the sum was less than 1), medium (the sum equaled 2) and high (the sum was between 3 and 4).

\section{Data analysis}

The following outcomes were analyzed across the entire sample and by socioeconomic status, education or income: the proportion of smokers who had made a quit attempt during the six months prior to the interview; the proportion of smokers who had visited a doctor in the six months prior to the interview; and the proportion of individuals that had received advice or help concerning quitting smoking, also stratified by type of advice or help offered. Poisson regression model was used to assess the relationship between socioeconomic status, education, or income and each of these outcomes, while adjusting for age and gender. 
The Stata version 9.0 (Stata Corp., College Station, USA) was used to take into account the complex sampling and weighting. In order to reduce non-coverage bias in the ITC Brazil survey, post-stratification adjustments were made to calibrate weights for smoking prevalence by city, sex and age group. For all analyses, p-values of $\leq 0.05$ were used to indicate statistical significance.

\section{Ethics}

The ITC Brazil Survey was approved by the Brazilian National Cancer Institute Ethics Review Board and by the Human Research Ethics Committee of the University of Waterloo.

\section{Results/outcomes}

Males comprised approximately half of the study sample. Forty-six percent of smokers were under 40 years of age and approximately $10 \%$ had less than five years of schooling. Approximately $40 \%$ of smokers reported a monthly income of less than US\$ 750 and $38.1 \%$ had a low socioeconomic status. Almost 93\% smoked on a daily basis and average daily cigarette consumption was 15.4 (Table 1).

An attempt to quit smoking during the six months prior to the interview had been made by $29.4 \%$ of the individuals interviewed, $31.5 \%$ in the low socioeconomic status group, $30.7 \%$ in the medium socioeconomic status group, and $25.3 \%$ in the high socioeconomic status group. Of this total, $41 \%$ had visited a doctor in last six months (of which $37.7 \%$ in the low socioeconomic status group, $35.9 \%$ in the medium socioeconomic status group, and $53.7 \%$ in the high socioeconomic status group), of which $57 \%$ had received some kind of advice or help concerning quitting smoking $58 \%$ in the low socioeconomic status group, $50.9 \%$ in the medium socioeconomic status group, and $62 \%$ in the high socioeconomic status group). On a whole, approximately $23 \%$ of smokers had received some kind of advice from their doctor concerning quitting smoking, $21.9 \%$ in the low socioeconomic status group, $18.3 \%$ in the medium socioeconomic status group, and $33.5 \%$ in the high socioeconomic status group. No statistical differences were found regarding attempts to quit smoking between individuals with different socioeconomic status after controlling for the effects of age and gender. However, among smokers who had attempted to quit smoking in the six months prior to the interview, individuals with high socioeconomic status were 1.65 times more likely to have received smoking cessation advice or help than those with low so- cioeconomic status $(\mathrm{p}=0.025)$ (Table 2). When we repeated the analyses mentioned in Table 2 also controlling for the city where the survey was conducted, results remained virtually unchanged (data not shown).

It is important to note that no statistically significant change in quit attempts in the six months preceding the interview was found for the categories of education and income presented in Table 1 (data not shown). Furthermore, smokers who had attempted to quit in the six months prior to the interview and who had at least a high school degree, visited a doctor and received advice to quit smoking 1.37 times ( $\mathrm{p}$ adjusted $=0.048$ ) and 2.00 times ( $p$ adjusted $=0.041$ ), respectively, more often than individuals in the elementary school or less category. Moreover, smokers who had attempted to quit in the six months prior to the interview and had a monthly household income of

\section{Table 1}

Sample characteristics of smokers aged 18 years and over. Brazil, 2008

\begin{tabular}{|c|c|}
\hline Characteristic & $\begin{array}{c}\text { Smokers (\%) } \\
{[n=1,215]}\end{array}$ \\
\hline \multicolumn{2}{|l|}{ Gender } \\
\hline Male & 52.2 \\
\hline Female & 47.8 \\
\hline \multicolumn{2}{|l|}{ Age-group (years) } \\
\hline $18-24$ & 12.2 \\
\hline $25-39$ & 33.9 \\
\hline $40-54$ & 35.6 \\
\hline $55+$ & 18.3 \\
\hline \multicolumn{2}{|l|}{ Educational level (years) } \\
\hline $0-4$ & 9.0 \\
\hline $5-10$ & 62.8 \\
\hline$\geq 11$ & 28.2 \\
\hline \multicolumn{2}{|l|}{ Average monthly income (US\$) } \\
\hline$<750$ & 38.1 \\
\hline $750-2,500$ & 45.8 \\
\hline$\geq 2,500$ & 16.1 \\
\hline \multicolumn{2}{|l|}{ Socioeconomic status * } \\
\hline Low & 37.2 \\
\hline Medium & 34.2 \\
\hline High & 28.6 \\
\hline \multicolumn{2}{|l|}{ Smoking status } \\
\hline Daily & 92.3 \\
\hline Weekly or monthly & 7.7 \\
\hline Average daily cigarette consumption & 15.4 \\
\hline
\end{tabular}

* Combination of the categories of educational level and average monthly income. 
Raw proportions (\%), crude prevalence rate ratio and adjusted prevalence rate ratio * of selected smoking cessation measures, by socioeconomic status.

\begin{tabular}{|c|c|c|c|c|c|}
\hline Smoking cessation measure & $\begin{array}{l}\text { Raw } \\
\text { proportions } \\
\text { (\%) }\end{array}$ & $\begin{array}{l}\text { Crude } \\
\text { prevalence } \\
\text { rate ratio }\end{array}$ & $\begin{array}{l}\text { Adjusted } \\
\text { prevalence } \\
\text { rate ratio }\end{array}$ & $95 \% \mathrm{Cl}$ & p-value \\
\hline $\begin{array}{l}\text { Current smokers who attempted to quit in } \\
\text { the past } 6 \text { months }\end{array}$ & 29.4 & - & - & - & - \\
\hline Low socioeconomic status & 31.5 & 1.00 & 1.00 & - & - \\
\hline Medium socioeconomic status & 30.7 & 0.97 & 0.94 & $0.75-1.20$ & 0.654 \\
\hline High socioeconomic status & 25.3 & 0.80 & 0.78 & $0.60-1.04$ & 0.165 \\
\hline $\begin{array}{l}\text { Current smokers who had attempted to quit } \\
\text { in the past } 6 \text { months who had visited } \\
\text { a doctor in the last } 6 \text { months }\end{array}$ & 41.0 & - & - & - & - \\
\hline Low socioeconomic status & 37.7 & 1.00 & 1.00 & - & - \\
\hline Medium socioeconomic status & 35.9 & 0.95 & 1.06 & $0.70-1.47$ & 0.926 \\
\hline High socioeconomic status & 53.7 & 1.42 & 1.54 & $1.11-2.04$ & 0.017 \\
\hline $\begin{array}{l}\text { Smokers who had visited a doctor in the } \\
\text { past } 6 \text { months who had received any kind of } \\
\text { advice or help concerning quitting smoking }\end{array}$ & 57.2 & - & - & - & - \\
\hline Low socioeconomic status & 58.0 & 1.00 & 1.00 & & - \\
\hline Medium socioeconomic status & 50.9 & 0.88 & 0.86 & $0.56-1.32$ & 0.479 \\
\hline High socioeconomic status & 62.3 & 1.07 & 1.09 & $0.75-1.58$ & 0.644 \\
\hline $\begin{array}{l}\text { Current smokers who had attempted to quit } \\
\text { in the past } 6 \text { months who had received any } \\
\text { kind of advice or help concerning quitting } \\
\text { smoking }\end{array}$ & 23.4 & - & - & - & - \\
\hline Low socioeconomic status & 21.9 & 1.00 & 1.00 & - & - \\
\hline Medium socioeconomic status & 18.3 & 0.84 & 0.89 & $0.51-1.55$ & 0.683 \\
\hline High socioeconomic status & 33.5 & 1.53 & 1.65 & $1.09-2.31$ & 0.025 \\
\hline
\end{tabular}

95\% $\mathrm{Cl}$ : 95\% confidence interval.

* Poisson regression was used to estimate adjusted (by age and gender) prevalence rate ratios.

US\$ 2,500 or more visited a doctor and received advice to quit smoking, 1.69 times (p adjusted $=0.008$ ) and 1.75 times ( $\mathrm{p}$ adjusted $=0.049$ ), respectively, more often than individuals with a monthly income of less than US\$ 750 (data not shown in a Table).

Of the smokers who had received some kind of advice or help to quit during a recent doctor's visit, 95.9\% received advice to stop smoking (95.3\% in the low socioeconomic status group, $95.7 \%$ in the medium socioeconomic status group, and $96.5 \%$ in the high socioeconomic status group), $28.6 \%$ received pamphlets or brochures on how to quit $22.3 \%$ in the low socioeconomic status group, $32.7 \%$ in the medium socioeconomic status group, and $30.1 \%$ in the high socioeconomic status group), $20.7 \%$ were referred to another service to help them to quit (25.4\% in the low socioeconomic status group,
$17.4 \%$ in the medium socioeconomic status group, and $19.7 \%$ in the high socioeconomic status group), $21.7 \%$ were prescribed a medication to help them stop smoking $(16.3 \%$ in the low socioeconomic status group, $20.1 \%$ in the medium socioeconomic status group, and $27.0 \%$ in the high socioeconomic status group), and $7.2 \%$ had called the "quitline" $(4.2 \%$ in the low socioeconomic status group, $11.5 \%$ in the medium socioeconomic status group, and $6.1 \%$ in the high socioeconomic status group). No statistical differences were found regarding the relationship between type of advice or help received and socioeconomic status (Table 3).

The proportion of individuals receiving each type of advice or help to quit smoking during a recent doctor's visit by respective education group ("high school further education" and "elementary school or less”) was: "advice to stop 
Raw proportions (\%), crude prevalence rate ratio and adjusted prevalence rate ratio * of type of advice or help received to quit smoking during a recent visit to the doctor, by socioeconomic status.

\begin{tabular}{|c|c|c|c|c|c|}
\hline $\begin{array}{l}\text { Type of advice or help received to quit } \\
\text { smoking during a recent visit to the } \\
\text { doctor }\end{array}$ & $\begin{array}{c}\text { Raw } \\
\text { proportions } \\
\text { (\%) }\end{array}$ & $\begin{array}{l}\text { Crude } \\
\text { prevalence } \\
\text { rate ratio }\end{array}$ & $\begin{array}{l}\text { Adjusted } \\
\text { prevalence } \\
\text { rate ratio }\end{array}$ & $95 \% \mathrm{Cl}$ & p-value \\
\hline $\begin{array}{l}\text { Current smokers who received advice to } \\
\text { stop smoking }\end{array}$ & 95.9 & - & - & - & - \\
\hline Low socioeconomic status & 95.3 & 1.00 & 1.00 & 1.00 & - \\
\hline Medium socioeconomic status & 95.7 & 1.00 & 1.00 & $0.94-1.06$ & 0.887 \\
\hline High socioeconomic status & 96.5 & 0.99 & 0.99 & $0.93-1.06$ & 0.770 \\
\hline $\begin{array}{l}\text { Current smokers who received pamphlets } \\
\text { or brochures on how to quit smoking }\end{array}$ & 28.6 & - & - & - & - \\
\hline Low socioeconomic status & 22.3 & 1.00 & 1.00 & 1.0 & - \\
\hline Medium socioeconomic status & 32.7 & 1.47 & 1.51 & $0.86-2.63$ & 0.148 \\
\hline High socioeconomic status & 30.1 & 1.35 & 1.29 & $0.75-2.23$ & 0.361 \\
\hline $\begin{array}{l}\text { Current smokers who were referred to } \\
\text { another service to help them quit }\end{array}$ & 20.7 & - & - & - & - \\
\hline Low socioeconomic status & 25.4 & 1.00 & 1.00 & 1.00 & - \\
\hline Medium socioeconomic status & 17.4 & 0.68 & 0.70 & $0.36-1.35$ & 0.286 \\
\hline High socioeconomic status & 19.7 & 0.78 & 0.76 & $0.42-1.38$ & 0.360 \\
\hline $\begin{array}{l}\text { Current smokers who were prescribed } \\
\text { medication to help them stop smoking }\end{array}$ & 21.7 & - & - & - & - \\
\hline Low socioeconomic status & 16.3 & 1.00 & 1.00 & 1.00 & - \\
\hline Medium socioeconomic status & 20.1 & 1.23 & 1.28 & $0.62-2.66$ & 0.509 \\
\hline High socioeconomic status & 27.0 & 1.66 & 1.71 & $0.86-3.39$ & 0.124 \\
\hline $\begin{array}{l}\text { Current smokers who called the quitline } \\
\text { for advice or information about quitting } \\
\text { smoking }\end{array}$ & 7.2 & - & - & - & - \\
\hline Low socioeconomic status & 4.2 & 1.00 & 1.00 & 1.00 & - \\
\hline Medium socioeconomic status & 11.5 & 2.74 & 2.70 & $0.73-9.99$ & 0.137 \\
\hline High socioeconomic status & 6.1 & 1.45 & 1.44 & $0.33-6.34$ & 0.631 \\
\hline
\end{tabular}

95\% $\mathrm{Cl}$ : 95\% confidence interval.

* Poisson regression was used to estimate adjusted (by age and gender) prevalence rate ratios.

smoking", 96.6\% compared to 92.8\%; "pamphlets or brochures on how to quit", $30.7 \%$ compared to $21.6 \%$; "referral to another service to help them to quit", $21 \%$ compared to $22.7 \%$; "prescription for stop-smoking medication", $25 \%$ compared to $19.5 \%$; "call to a telephone counseling service", $5.8 \%$ compared to $9.3 \%$. The proportion of individuals receiving each type of advice or help for quitting smoking during a recent doctor's visit by respective income group ("US\$ 2,500 or more" and "less than US\$ 750") was: "advice to stop smoking”, 98.8\% compared to $95.4 \%$; "pamphlets or brochures on how to quit", $34.2 \%$ compared to $24.6 \%$; "referral to another service to help to quit”, $18.7 \%$ compared to $24.6 \%$; "prescription for stop-smoking medication”, $24.5 \%$ compared to $15.8 \%$; "call to the quitline", $1.6 \%$ compared to
$4.1 \%$. No statistical differences were found regarding the relationship between type of advice or help received and education or income (data not shown).

\section{Discussion}

The ITC Brazil Survey found that $29.4 \%$ of the population, equivalent to a total of approximately 350,000 smokers, across the three cities had tried to quit smoking in the six months prior to the survey. When this assessment was carried out only among individuals with low socioeconomic status, it was also found that this subgroup had been very motivated to try to quit smoking (31.5\%, equivalent to approximately 
130,000 smokers). Moreover, approximately $45 \%$ of smokers attempted to quit in the 12 months prior to the survey, $50.7 \%$ in the low socioeconomic status group, $43.6 \%$ in the medium socioeconomic status group, and $39.8 \%$ in the high socioeconomic status (data not shown). This rate is $40 \%$ higher than that observed in Mexico, another upper-middle-income country ${ }^{15}$. It is likely that the high proportion of individual intentions to quit observed in Brazil are a reflection of the effects of a number of legislative actions to reduce tobacco use adopted by the country since 19863 . The fact that smoking declines with increasing years of education 3 , means that the results of this study may have important implications for public health. However, one of the challenges for National Tobacco Control Programs is to understand the socioeconomic and cultural characteristics of the smoker population to be able to tailor cessation strategies to different subgroups of smokers who are trying to quit tobacco use 16 . The effectiveness of smoking control programs is, therefore, a function of efficacy of interventions, adherence to the type of intervention, and the tools employed to recruit smokers 16,17.

Although individuals with low socioeconomic status were less likely to consult a doctor or other health professional, this group showed the same level of willingness to quit smoking and received the same level of smoking cessation advice or help during their consultation as individuals with high socioeconomic status. Moreover, we found that smokers received advice to stop smoking more often than they received other types of help to stop smoking, such as prescriptions for medication to help give up smoking, irrespective of socioeconomic status. This combined data seems to demonstrate a shortfall in tobacco control actions, suggesting that effective "exposure" of smokers to cessation services is an essential issue to consider when defining health policies 2; quit rates are estimated to increase $200 \%$ with pharmacologic and behavioral treatment 18 , compared to informal or ineffective evidence-based-treatments. Furthermore, after considering the effect of multiple quit attempts among individuals seeking formal help that fail at their first attempt, population quit rates are likely to increase even more 19.

The frequency of "exposure" to cessation services and the type of help received reflects the multidimensional relationship between the extent of public and other tobacco control efforts in the country, the sociocultural context, income level, and access to services. It is important to note that the overall rate of doctor visits during the six months prior to the survey $(41 \%)$ was similar to rates observed in developed countries, such as the Netherlands (46\%), and higher than rates observed in other upper-middle-income countries, such as Mexico (26\%) 11. Furthermore, the percentage of individuals who had received advice concerning quitting smoking (57.2\%) was much higher than in some high-income countries, such as Germany (30.6\%) and France (25.9\%) 15. Finally, in Brazil, in contrast to many countries, individuals with low socioeconomic status were as motivated to quit smoking ( $\mathrm{p}$ adjusted $=0.165$ ) and received as much smoking cessation support from doctors ( $\mathrm{p}$ adjusted = 0.644 ) as individuals with high socioeconomic status 20 . These findings suggest that the broad set of legislative, health care, educational and economic interventions implemented in Brazil since 1986 aimed at promoting smoking cessation likely reached different population subgroups with the same level of effectiveness.

Although Brazil has one of the largest public health systems in the world and has a strong tobacco control program, the implementation of smoking cessation treatment still faces several challenges. The number of municipalities providing assistance to the population constantly fluctuates, mainly due to inconsistent conveyance of information and supply of drugs to treat severe tobacco dependence, and lack of organization of local programs in more deprived areas, which in turn have higher proportions of individuals with low educational levels $3,6,7$. This situation reinforces the fact that the smoking problem in Brazil reflects the country's social inequalities (for example, approximately $11 \%$ of the Brazilian population aged 15 years and over, equivalent to 16 million people, including four million smokers, are illiterate; approximately $9 \%$ of the population, equivalent to 12 million people, of whom three million are smokers, live on less than US\$ $2.0 /$ day) ${ }^{3}$. Thus, although Brazil is the world's seventh largest economy, health and socioeconomic disparities are a major challenge for policymakers 5,6 .

Some of our findings were consistent with data derived from the Global Adult Tobacco Survey (GATS-Brazil) ${ }^{3}$, a nationally representative crosssectional survey conducted between August and November 2008, reinforcing the impact of not increasing access to smoking cessation services among the most vulnerable populations (i.e., higher smoking prevalence rates). For instance, of the 10 million smokers aged 15 years and over who attempted to quit in the 12 months prior to the survey, around six million, most of whom (4.7 million) had not completed high school, did not receive counseling for smoking cessation. It is important to note that differential access to smoking cessation interventions among smok- 
ers with different educational levels was also observed in other countries which implemented GATS, such as the Philippines, the Russian Federation, Poland and Vietnam ${ }^{21}$. Future research must consider and aim to address the specific socioeconomic determinants that attenuate the impact of tobacco control policies among more disadvantaged populations.

The GATS-Brazil also found that lower nicotine dependence levels were associated with living in rural areas, having a lower level of education and earning less money, suggesting that daily cigarette consumption is influenced by socioeconomic issues ${ }^{3}$. Counseling is more effective in treating less addicted individuals 22 , and therefore access to this cost-effective intervention should be increased for people who will benefit most from this non-pharmacological treatment. Low and middle income countries seeking to create or strengthen treatment services should propose tobacco control actions that consider infrastructure and resource limitations, cultural context and experience of past actions. Results from the ITC-Brazil survey showed, for instance, that smokers, especially those with low socioeconomic status, received advice to quit smoking more often than they received prescriptions for medications to help stop smoking, thus reinforcing the importance of increasing willingness to quit smoking and access to health prevention services among underprivileged people. It is important to note that, at the time this survey was conducted, according to the National Tobacco Control Program 23, only 9\% of public health units (145 of a total of 1,641 units) in the three cities were able to offer behavioral counseling and, when applicable, pharmacoterapy for smokers. Our findings also demonstrated the importance of sensitizing doctors to encourage smokers to use the free telephone counseling service, particularly those with a low level of education and monthly income.

Several "reactive-recruitment" actions implemented under the Brazilian National Tobacco Control Program have been aimed at reducing problems related to accessibility and availability of help to stop smoking thus also addressing social inequalities. It is important to highlight for instance the use of emotionally powerful images on cigarette packages illustrating the negative physical impacts or human suffering due to smoking, combined with the free telephone counseling service, which have a great cognitive impact with smokers with lower educational levels $3,12,24$. On the other hand, it has been reported that individuals with lower educational levels are less aware of anti-smoking propaganda broadcast on television ${ }^{3}$, even though almost $100 \%$ of households have a television 25 . This fact reinforces the need to further develop strategies that focus on specific population subgroups.

Our results also showed that raising awareness of tobacco-related problems among smokers and increasing access to support may be not sufficient. Indeed, out of the total number of smokers who had visited a doctor in the last six months, only $57.2 \%$ received smoking cessation advice or help. These numbers show that a large proportion of doctors and other health professionals still do not give due importance to smoking as a disease and risk factor for other diseases, despite efforts in Brazil to encourage doctors and health professionals to apply evidence-based guidelines for smoking cessation. Sensitization and training of health professionals regarding smoking as a risk factor for about 50 diseases and as a disease in itself (nicotine dependence) is fundamental. An important strategy would be to include smoking and treatment in the curriculum of medical degree programs. Since smoking was only recently recognized by the WHO as a disease 26 , several schools of medicine and other health fields do not include the problem in this category. Consequently, students are not trained to ask patients about tobacco use and graduate without knowing how to recognize and treat tobacco dependency or gives recommendations regarding cessation.

The above-mentioned topics are covered by article 14 of theWHO FCTC which encourages the development of effective measures to promote cessation of tobacco use and adequate treatment for tobacco dependence, including the promotion of $100 \%$ smoke-free environments and an increase in access to and affordability of treatments 2 . In other words, it is important to understand that not all smokers are the same, and that certain types of smokers need to be "won over" as "potential clients" of an intervention program aimed at addressing their specific needs.

This study has some limitations. Although the coverage of telephone lists in Brazil was quite high (São Paulo 77\%, Rio de Janeiro 75.2\% and Porto Alegre 86.6\%) 7,27, smokers without landlines are likely to be from lower socioeconomic status groups and may respond differently to selected smoking cessation questions than smokers with lower socioeconomic status in our sample 27 . Therefore, it is possible that the overall proportion of smokers in the three cities surveyed that did not receive advice regarding stopping smoking while attempting to quit is greater than that shown by the study $(<23.4 \%)$. Moreover, in household telephone non-contacts and smokers non-responses did not occur ran- 
domly, the external validity of our results may have been affected 29 . For instance, another telephone survey conducted in Brazil in 2009 was successful in contacting $57 \%$ of households 29 , probably indicating that the external validity of the ITC-Brazil results may have been limited due the electronic phone number directory used to sample households or to caller training.

Finally, our data is subject to biases resulting from self-reporting. For example, there may be an increasing tendency to over-report smoking cessation attempts due to the growing stigma of smoking, and also because tobacco use was the main interest of ITC-Brazil investigation 30 .

\section{Conclusions}

In many countries, including Brazil, national regulatory measures to control tobacco use are not necessarily accompanied by an adequate increase in access to health services for all popula- tion groups 5,6. It is therefore important that lowincome populations, characterized by higher smoking prevalence ${ }^{3}$, also benefit from potential reductions in tobacco-related complications. With respect to these groups, Brazil still faces problems that are similar to those faced by other nations. Nevertheless, Brazil's general success in reducing smoking prevalence rates serves as a model for other countries.

It is essential to establish progressively a national system for the epidemiological surveillance of tobacco consumption and related social, economic and health indicators, as stated in article 20 of the WHO FCTC 2 , in order to better understand the evolution of the tobacco epidemic. This will allow countries who have implemented strong tobacco control policies to continue to make progress in tobacco control by proposing new strategies to prevent initiation of tobacco use and encourage cessation among those who started, or continued smoking in a "more hostile" environment.

\section{Resumen}

El aumento de la efectividad de las políticas dirigidas a la prohibición del tabaco requiere un mayor entendimiento de cuestiones culturales y socioeconómicas, que forman parte del universo de los fumadores. El objetivo de este artículo es explorar la asociación entre status socioeconómico y "puntos intermedios seleccionados", relacionados con la prohibición del tabaco en Brasil. En base a la investigación ITC-Brasil, se recogió información de una muestra representativa de la población urbana adulta de fumadores (2009, $N=1.215$ ), tras ajustarla por edad y sexo, no se encontraron diferencias estadísticamente significativas en las tentativas de dejar de fumar en los últimos 6 meses según el status socioeconómico. No obstante, los fumadores con un elevado status socioeconómico visitaron un médico 1,54 veces más que aquellos con un bajo status socioeconómico $(p=0,017)$ y también recibieron 1,65 veces más asesoría para dejar de fumar $(p=0,025)$. Los hallazgos indican que las disparidades entre salud y status socioeconómico todavía representan un desafío para los gestores con el fin de aumentar el impacto poblacional de las acciones de control del tabaco en el mundo.

Cese del Tabaquismo; Accesibilidad a los Servicios de Salud; Política de Salud

\section{Contributors}

A. S. Szklo participated in data processing, analysis and as lead author in the preparation and elaboration of this article. J. F. Thrasher, C. Perez and V. C. Figueiredo provided advice regarding data analysis and participated as co-authors in the preparation and elaboration of this article. G. Fong and L. M. Almeida participated as co-authors in the preparation and elaboration of this article.

\section{Acknowledgements}

We are grateful to the Project Management Staff (Janine Ouimet and Anne Quah) of the ITC Project at the University of Waterloo for their contributions on all aspects of the ITC-Brazil survey. We would also like to thank the team members of the Data Management Center of the ITC Project at the University of Waterloo, including: Christian Boudreau, PhD, Pete Driezen, MSc, Ruth Loewen, MA, and Mary E. Thompson, PhD. Thanks are also due to the technical staff from Expertise who conducted the field work. 


\section{References}

1. World Health Organization. Global health risks: mortality and burden of disease attributable to selected major risks. http://www.who.int/healthin fo/global_burden_disease/GlobalHealthRisks_re port full.pdf (accessed on 22/Jan/2012).

2. World Health Organization. The Framework Convention on Tobacco Control. http://www.who.int/ fctc/text_download/en/index.html (accessed on 22/Jan/2012)

3. Instituto Nacional de Câncer. Global adult tobacco survey: Brazil report. http://www.who.int/tobacco/ surveillance/en_tfi_gats_2010_brazil.pdf (accessed on $22 / \operatorname{Jan} / 2012$ ).

4. The World Bank. Country and lending groups. http://data.worldbank.org/about/country-classi fications/country-and-lending-groups (accessed on $22 / \mathrm{Jan} / 2012$ ).

5. United Nations Development Programme. Human development report 2010. http://hdr.undp.org/en/ reports/global/hdr2010/chapters (accessed on 22/ Jan/2012).

6. Almeida C, Travassos C, Porto S, Labra ME. Health sector reform in Brazil: a case study of inequity. Int J Health Serv 2000; 30:129-62.

7. Instituto Brasileiro de Geografia e Estatística. An analysis of the Brazilian population social conditions - 2008. http://www.ibge.gov.br/english/ estatistica/populacao/condicaodevida/indicado resminimos/sinteseindicsociais2008/default.shtm (accessed on 22/Jan/2012).

8. Raw M, Regan S, Rigotti NA, McNeill A. A survey of tobacco dependence treatment services in 36 countries. Addiction 2009; 104:279-87.

9. Hastings G, McLean N. Social marketing, smoking cessation and inequalities. Addiction 2006; 101:303-4.

10. Binson D, Canchola JA, Catania JA. Random selection in a national telephone survey: a comparison of the kish, next-birthday and last-birthday methods. J Off Stat 2000; 16:53-60.

11. Abramson JH, Gahlinger PM. Computer programs for epidemiologists PEPI version 3.01. Powys: Brixton Books; 1999.

12. Thrasher JF, Villalobos V, Szklo A, Fong GT, Perez C, Sebrie E, et al. Assessing the impact of cigarette package health warning labels: a cross-country comparison in Brazil, Uruguay and Mexico. Salud Pública Méx 2010; 52 Suppl 2:S206-15.

13. Howe LD, Galobardes B, Matijasevich A, Gordon D, Johnston D, Onwujekwe O, et al. Measuring socioeconomic position for epidemiological studies in low- and middle-income countries: a methods of measurement in epidemiology paper. Int J Epidemiol 2012; 41:871-86.
14. Samet J, Howard CA, Coultas DB, Skipper, BJ. Acculturation, education, and income as determinants of cigarette smoking in New Mexico Hispanics. Cancer Epidemiol Biomarkers Prev 1992; 1:235-40.

15. Borland R, Li L, Driezen P, Wilson N, Hammond D, Thompson ME, et al. Cessation assistance reported by smokers in 15 countries participating in the International Tobacco Control (ITC) policy evaluation surveys. Addiction 2012; 107:197-205.

16. Glasgow RE, Lichtenstein E, Marcus AC. Why don't we see more translation of health promotion research to practice? Rethinking the efficacy-toeffectiveness transition. Am J Public Health 2003; 93:1261-7.

17. Thyrian JR, John U. Population impact - definition, calculation and its use in prevention science in the example of tobacco smoking reduction. Health Policy 2007; 82:348-56.

18. Abrams DB, Graham AL, Levy DT, Mabry PL, Orleans CT. Boosting population quits through evidence-based cessation treatment and policy. Am J Prev Med 2010; 38(3 Suppl):S351-63.

19. Levy DT, Graham AL, Mabry PL, Abrams DB, Orleans CT. Modeling the impact of smoking-cessation treatment policies on quit rates. Am J Prev Med 2010; 38(3 Suppl):S364-72.

20. U.S. Department of Health and Human Services. Smoking and tobacco control monograph, n. 5. http://cancercontrol.cancer.gov/tcrb/monogra phs/5/m5_complete.pdf (accessed on 22/Jan/ 2012).

21. World Health Organization. Global adult tobacco survey. http://www.who.int/tobacco/surveillance/ gats/en/ (accessed on 22/Jan/2012).

22. Fiore MC, Jaén CR, Baker TB, Bailey W, Benowitz $\mathrm{N}$, Curry S, et al. Treating tobacco use and dependence: 2008 update. Clinical practice guideline. Rockville: U.S. Department of Health and Human Services; 2008.

23. Instituto nacional de Câncer. Programa Nacional de Controle do Tabagismo. http://www1.inca.gov. $\mathrm{br} /$ tabagismo (accessed on 20/Sep/2012).

24. Brendl SM, Higgins ET, Lemm K. Sensitivity to varying gains and losses: the role of self-discrepancies and event framing. J Pers Soc Psychol 1995; 69:1028-51.

25. Instituto Brasileiro de Geografia e Estatística. Pesquisa Nacional por Amostra de Domicílios, 2009. http://www.ibge.gov.br/english/estatistica/popu lacao/trabalhoerendimento/pnad2009/default. shtm (accessed on 22/Jan/2012). 
26. World Health Organization. International statistical classification of diseases and related health problems, 10th revision. http://apps.who.int/clas sifications/apps/icd/icd10online (accessed on 22/ Jan/2012).

27. Bernal R, Silva NN. Cobertura de linhas telefônicas residenciais e vícios potenciais em estudos epidemiológicos. Rev Saúde Pública 2009; 43:421-6.

28. Keeter S, Miller C, Kohut A, Groves RM, Presser $\mathrm{S}$. Consequences of reducing nonresponse in a national telephone survey. Public Opin Q 2000; 64:125-48.
29. Ministério da Saúde. Vigilância de Fatores de Risco e Proteção para Doenças Crônicas por Inquérito Telefônico. http://portal.saude.gov.br/portal/ar quivos/pdf/vigitel2009_220610.pdf (accessed on 20/Sep/2012).

30. Gallus S, Tramacere I, Boffetta P, Fernandez E, Rossi S, Zuccaro P, et al. Temporal changes of underreporting of cigarette consumption in populationbased studies. Tob Control 2011; 20:34-9.

Submitted on 14/Jun/2012

Final version resubmitted on $08 /$ Oct $/ 2012$

Approved on 31/Oct/2012 